\title{
Homocysteine disulphides and vascular disease
}

\author{
Mauro Iuliano ${ }^{\mathrm{a}}$, Gaetano De Tommaso ${ }^{\mathrm{a}}$ and Raffaele Ragone ${ }^{\mathrm{b}, *}$ \\ ${ }^{a}$ Dipartimento di Chimica, Università Federico II, Naples, Italy \\ ${ }^{\mathrm{b}}$ Dipartimento delle Scienze Biologiche, Università Federico II, Naples, Italy
}

The final draft of this manuscript was ready on occasion of the retirement of Professor Liberato Ciavatta, who has been an inspiration to a generation of students. M.I., G.D.T. and R.R. wish to dedicate this paper to his integrity and rigor in scientific research.

\begin{abstract}
The total plasma concentration of homocysteine is a marker of this amino acid's atherogenic potential. However, the homocysteine pool exists almost entirely as oxidized homocysteine equivalents (OHcyE), composed of homocystine and cysteinehomocysteine disulphides (20-30\%), and protein-bound disulphide (70-80\%). We have noticed that the total concentration of OHcyE in injured coronary artery tissue is higher than the aqueous solubility of homocystine $\left(\sim 1.4-1.5 \times 10^{-3} \mathrm{~mol} \mathrm{~kg}^{-1} \mathrm{versus}^{-1.1}\right.$ $\sim 0.6 \mathrm{~mol} \mathrm{~kg}-1)$. Based on the measurement of the solubility of homocystine in a plasma-mimetic condition $\left(0.17 \mathrm{~mol} \mathrm{~kg}^{-1}\right.$ $\mathrm{NaCl}$ at $37^{\circ} \mathrm{C}$ ), we have estimated that $\mathrm{OHcyE}$ may really reach their saturation limit in the vascular tissue $\left(0.93-1.02 \times 10^{-3}\right.$ $\mathrm{mol} \mathrm{kg} \mathrm{k}^{-1}$ ), above which their deposition as solid phase may occur. This means that significant leakage of intracellular fluid can promote OHcyE crystallization in tissue fluids, which may serve to initiate inflammation. We speculate that deposition of OHcyE crystals could damage blood vessels and act as a primer of homocysteine-triggered inflammation, thus being along the causal pathway that leads to vascular dysfunction.
\end{abstract}

Keywords: Atherosclerosis, cardiovascular disease, homocysteine, homocystine solubility, risk factors, vascular dysfunction

Abbreviations: OHcyE, oxidized homocysteine equivalents; DPP, differential pulse polarography

\section{Introduction}

Demethylation of the essential amino acid methionine produces the thiolic non-proteinogenic amino acid homocysteine [1]. Mild to moderate elevations of blood homocysteine have been associated with high risk of coronary heart disease and other vascular alterations [2-4]. Even though a causal role of homocysteine in cardiovascular disease remains to be established [5-7], it is believed that homocysteine excess may damage vascular tissue, so that blood ho-

*Corresponding author: Raffaele Ragone, Dipartimento delle Scienze Biologiche, Università Federico II, via Mezzocannone 16 , 80134 Naples, Italy. Tel.: +39 081253 6682; Fax: +39 199707 0716582; E-mail: raffrag@gmail.com. mocysteine is currently considered as an independent index of vascular risk [8-10]. Mechanisms underlying homocysteine-associated vascular injury are under investigation [11,12]. Till now, almost all homocysteine-concerned research has assumed that elevation of the total plasma concentration of this amino acid (free and protein-bound) is a marker of its atherogenic potential. However, free homocysteine comprises three distinct fractions, i.e., reduced homocysteine, homocysteine-homocysteine homo-disulphide (homocystine) and cysteine-homocysteine hetero-disulphide. Since the reduced form barely amounts to $1-2 \%$ of the body's total homocysteine, the homocysteine pool exists almost entirely as homocystine and cysteinehomocysteine (20-30\%), also referred to as 'oxidized homocysteine equivalents' (OHcyE), and protein- 
bound disulphide $(70-80 \%)[13,14]$. It is also worth considering that the total plasma concentration of cysteine, a proteinogenic amino acid that is the lower structural homologue of homocysteine because of one less $-\mathrm{CH}_{2}$ - group in the side-chain, is 20 - to 30 -fold higher than that of homocysteine, and the concentration of reduced cysteine is $\sim 70$-fold higher than that of reduced homocysteine $(5.0 \pm 3.6$ versus $0.07 \pm 0.02 \mu \mathrm{mol} / \mathrm{L}$, mean \pm s.d.) [15]. Nevertheless, there is no evidence that cysteine causes vascular damage, but a toxic effect of homocysteine on endothelial cells has been widely claimed [12,16-18], possibly through thrombosispromoting inflammatory pathways [19].

Recently, it has been pointed out that homocystine is the upper structural homologue of cystine (the homodisulphide of cysteine) [20], which is known to be scarcely soluble [21] and therefore capable to form kidney stones in genetically-disposed patients [22]. By analogy, it has been hypothesized [20] that vascular injury could be mechanically primed by the formation of homocystine crystals in the bloodstream, which could transiently grow after methionine intake and then dissolve during the time lag needed to reach basal conditions. In spite of the fact that, likely for the above reason, homocystine precipitates have never been found in endothelial cells or other tissues, it is worth mentioning that, in a population of patients with heart disease, levels of OHcyE were close to $1.4-1.5 \times 10^{-3} \mathrm{~mol}$ $\mathrm{kg}^{-1}$, which is $\sim 15$ fold higher than in normal coronary artery [23] (see Discussion for more details). At a glance, this elevation corresponds to a concentration of OHcyE higher than the aqueous solubility of homocystine at room temperature (unpublished data from our lab), and is affected by a statistical variability significantly lower than that observed in plasma. Indeed, the saturation concentration of OHcyE in the occluded coronary artery tissue can be reasonably placed between $\sim 5 \times 10^{-4}$ and $\sim 0.9-1.0 \times 10^{-3} \mathrm{~mol} \mathrm{~kg}^{-1}$ at the plasma ionic strength, depending on the relative abundance of cysteine-homocysteine and homocystine (see Discussion for more details). The equilibrium relationship involving cystine, homocystine and mixed disulphide under physiological concentrations of cysteine and homocysteine has been previously investigated $[14,24,25]$.

Although intracellular water also contains proteins, lipids, polysaccharides, and other species that may influence phase transitions, prevention and treatment of solid deposition in the human body, such as crystals of xanthine, uric acid and urates, cystine, oxalates, etc, are based on the understanding of the physicochemi- cal properties underlying the precipitation of the substances involved [26]. Pursuing this idea, we have measured the solubility of homocystine in aqueous sodium chloride solutions at physiological temperature.

\section{Materials and methods}

\subsection{Chemicals}

Purissimum grade $(\geqslant 99.0 \%) D L$-homocystine [meso -4,4'-dithio-bis(2-aminobutanoic acid)] was purchased from Fluka. Ultra-pure $(\geqslant 99.99 \%)$ sodium chloride and sodium azide from Baker and Aldrich, respectively, were dried at $120^{\circ} \mathrm{C}$ and stored in a dryer before use. Surfactant and perchloric acid solutions were prepared by diluting Triton X-100 as obtained from LKB Bromma and purum p.a. $\mathrm{HClO}_{4}$ from Merck, respectively.

\subsection{Solubility measurements}

Differential pulse polarography (DPP) has become and remains an appreciated and trusted method in the study of solutions, thanks to the high reproducibility of the experimental curves. Therefore, the solubility $\left(m_{I}, \mathrm{~mol} \mathrm{~kg}^{-1}\right)$ of homocystine was evaluated by this technique, based on the semireaction

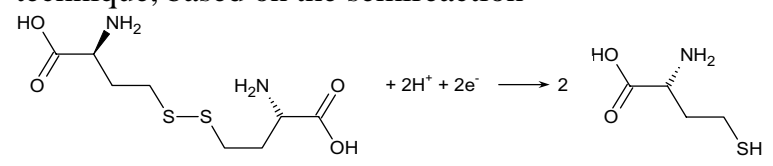

Saturated homocystine solutions were prepared with a leaching apparatus suitable to prevent solid particles from coming into contact with the magnetic stirrer. In fact, preliminary measurements have showed an increase of solubility over periods of weeks when the solid was in mechanical contact with the stirrer, because the solid was transformed into a phase made of smaller particles. To avoid grinding by the stirrer, solid homocystine was wrapped up in a highly retentive filter paper (Whatman 42) bag. This in turn was kept immersed in a glass cylinder containing sodium chloride solution, to which $0.1 \% \mathrm{NaN}_{3}$ was added to prevent decomposition, while continuously stirring with a magnetic bar (Fig. 1). The cylinder was then placed in a thermostated water bath at $37.00 \pm 0.05^{\circ} \mathrm{C}$ and the homocystine concentration was monitored in the time, until it reached a constant value, which usually took place in about 10-15 days. Finally, polarographic assays were performed when an exactly weighed aliquot of the saturated homocystine solution was added to $0.1 \mathrm{~mol} \mathrm{~kg}^{-1}$ 


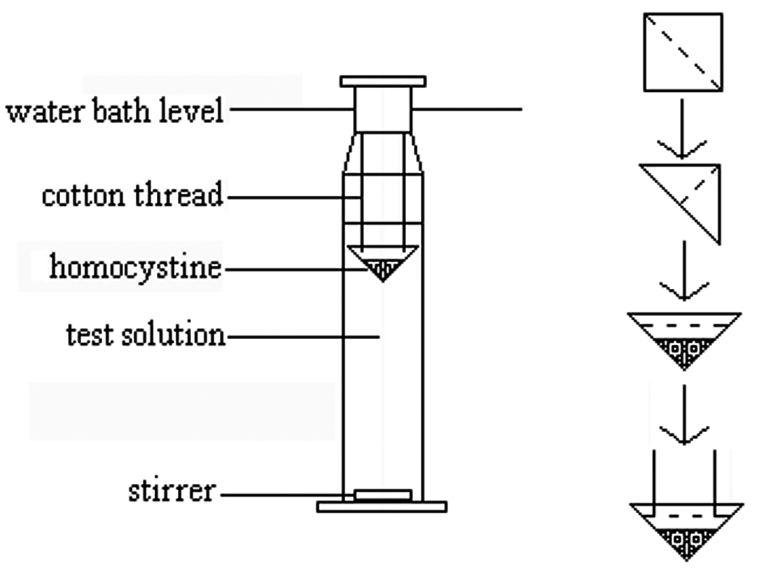

Fig. 1. The apparatus for preparation of saturated homocystine solutions.

$\mathrm{HClO}_{4}$ and $0.003 \%$ Triton X-100 solution to remove the signal drift caused by the sudden intensity increase of the diffusion current. Air-free samples were obtained by bubbling with nitrogen for $15 \mathrm{~min}$ and DPP traces were recorded with a Metrohm 747 VA model dropping mercury electrode apparatus interfaced with a Metrohm 746 VA model trace analyzer, using saturated $\mathrm{Ag} / \mathrm{AgCl}$ and $\mathrm{Pt}$ as reference and working electrodes, respectively. The instrumental settings were as follows: $4 \mathrm{mV} / \mathrm{s}$, scan rate; $50 \mathrm{mV}$, pulse amplitude; $60 \mathrm{~ms}$, pulse time; $500 \mathrm{~ms}$, drop lifetime. The potential sweep was from -1200 to $-50 \mathrm{mV}$ and the peak position around $E_{p}=-710 \mathrm{mV}$ with a half-peak width $\mathrm{w}_{1 / 2}=160 \mathrm{mV}$ (Fig. 2). As no substantial difference was observed between the solubilities of the optically active $D$ and $L$ enantiomers, and that of the optically inactive $D L$ meso diastereomer, the less expensive $D L$ homocystine was employed, and its concentration was calculated using a calibration curve based on standard solutions (Fig. 3). Three replicates were run for each point. All solubilities were expressed in $\mathrm{mol} \mathrm{kg}^{-1}$ to avoid the intrinsic temperature dependence of molar units caused by volume expansion. Anyway, the very low saturating levels of all homocystine disulphides do not produce any substantial concentration difference between these units, and both can be interchangeably used for practical use. All calculations were performed with the program Scientist version 2.0 from Micromath, Saint Louis, Missouri.

\section{Results}

Despite the fact that homocystine is a double zwitterion structurally homologous to cystine, the depen-
Table 1

Solubility of $D L$-homocystine ${ }^{\mathrm{a}}$

\begin{tabular}{cc}
\hline $\begin{array}{c}I \\
\left(\mathrm{~mol} \mathrm{~kg}^{-1}\right)\end{array}$ & $\begin{array}{c}m_{I} \pm \text { s.e.m. }^{\mathrm{b}} \\
\left(10^{-3} \mathrm{~mol} \mathrm{~kg}^{-1}\right)\end{array}$ \\
\hline 0.0000 & $0.633 \pm 0.003$ \\
0.1501 & $1.067 \pm 0.003$ \\
0.2485 & $1.060 \pm 0.003$ \\
0.2991 & $1.191 \pm 0.003$ \\
0.3574 & $1.115 \pm 0.002$ \\
0.4010 & $1.316 \pm 0.002$ \\
0.6822 & $1.381 \pm 0.002$ \\
0.8515 & $1.293 \pm 0.002$ \\
1.0034 & $1.082 \pm 0.002$ \\
\hline${ }^{\mathrm{a}}$ measurements & performed at \\
$37^{\circ} \mathrm{C}$. & \\
$\mathrm{b}_{\text {standard error }}$ of the mean.
\end{tabular}

dence of its solubility on the $\mathrm{NaCl}$ concentration is nonmonotonic, whereas the solubility of cystine has been found to increase monotonically up to $4.4 \mathrm{~mol} \mathrm{~kg}^{-1}$ $\mathrm{NaCl}$ [27]. Indeed, at $\mathrm{NaCl}$ concentrations covering the physiological range, homocystine exhibits 'salting-in' behavior, with the solubility increasing with increasing ionic strength. Instead, higher salt concentrations have a 'salting-out' effect, and the solubility decreases with increased ionic strength (see Table 1). Solubility values were therefore fitted either to a parabolic function:

$$
\ln m_{I}=\ln m_{0}+a C_{S}+b C_{S}^{2}
$$

or with a two-parametric solubility dependence that is suitable to describe the activity coefficients of zwitterionic amino acids [28]:

$$
\begin{aligned}
\ln m_{I} & =\ln m_{0}-\log \gamma_{ \pm}=\ln m_{0}-2 \chi_{A B} C_{S} \\
& -\xi_{A B B} m_{I} C_{S}^{2}-4 \omega_{A A B} m_{I} C_{S}
\end{aligned}
$$

In these equations, $m_{0}$ is the solubility at zero ionic strength, $a$ and $b$ are empirical fitting parameters, $\gamma_{ \pm}$ is the mean molal activity coefficient, $\chi_{A B}, \xi_{A B B}$ and $\omega_{A A B}$ are Pitzer-type interaction parameters [29,30], and $C_{S}$ is the salt concentration, which equals the ionic strength $(I)$ for a monovalent salt like $\mathrm{NaCl}$.

Best fitting of data is graphically represented in Fig. 4. Use of Eq. (1) gave $a=2.63 \pm 0.17 \mathrm{~kg} \mathrm{~mol}^{-1}$ (mean \pm s.d.) and $b=-2.11 \pm 0.21 \mathrm{~kg}^{2} \mathrm{~mol}^{-2}$ (mean \pm s.d.) $\left(R^{2}=0.895\right)$, whereas equation 2 resulted in $\chi_{A B}=-2.51 \pm 1.60 \mathrm{~kg} \mathrm{~mol}^{-1}$ (mean \pm s.d.), $\xi_{A B B}=1837 \pm 552 \mathrm{~kg}^{3} \mathrm{~mol}^{-3}$ (mean \pm s.d.), and $\omega_{A A B}=475 \pm 689 \mathrm{~kg}^{2} \mathrm{~mol}^{-2}$ (mean \pm s.d.) $\left(R^{2}=0.902\right)$. A discussion on physical meaning and values of these coefficients is outside the scope of this study. At present, it is most important to check whether homocystine can achieve such levels in the body that precipitation in the tissue may occur. In general, ionic 


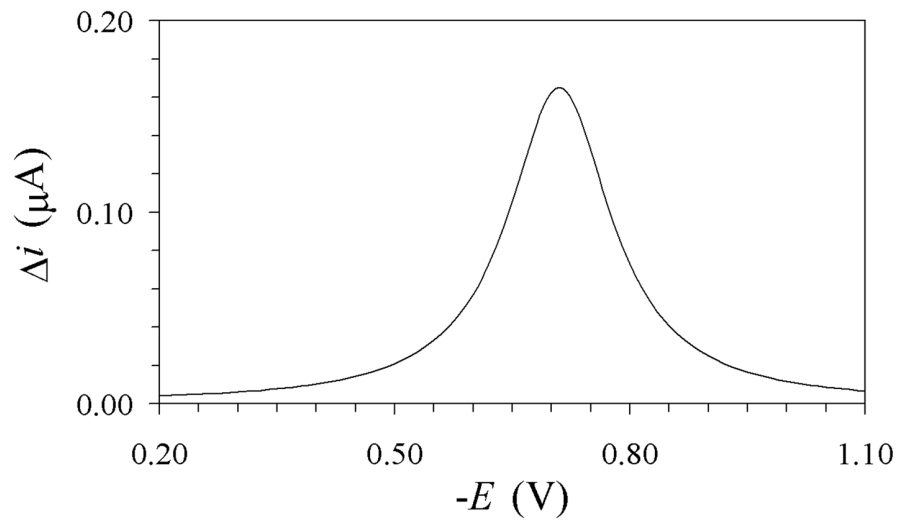

Fig. 2. Differential pulse polarogram for $D L$-homocystine reduction. The curve represents the dependence of the current passing through the system $(\Delta i, \mu \mathrm{A})$ on the electrochemical potential of the dropping electrode $(E, \mathrm{~V})$.

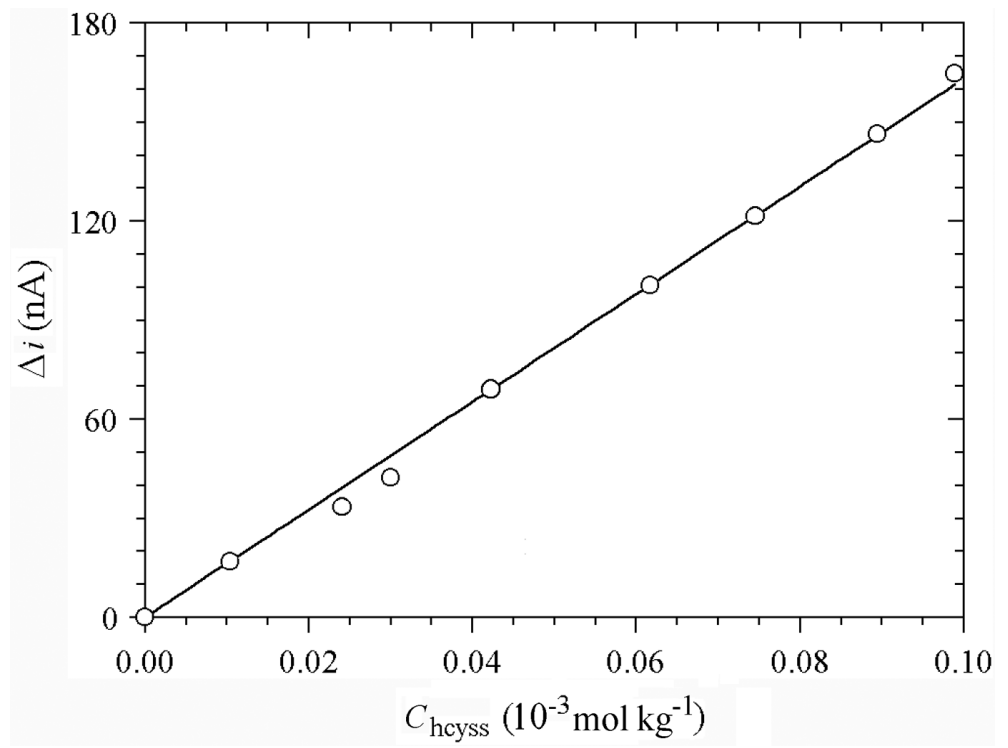

Fig. 3. Calibration curve for $D L$-homocystine. The equation resulting from the linear regression analysis of the capacity current $(\Delta i$, nA) versus the concentration of standard solutions $\left(C_{\mathrm{hCyss}}, 10^{-3} \mathrm{~mol} \mathrm{~kg}^{-1}\right)$ was $\mathrm{y}=1631.09 \mathrm{x}\left(R^{2}=0.999\right)$.

strength is the physicochemical factor that largely dominates the solubility of charged solutes. Thus, the use of $\mathrm{NaCl}$ alone is sufficient to mimic effects that may occur in vivo, whenever caused by the contribution of salts of different nature. It can be easily estimated by equations 1 and 2, respectively, that the solubility of homocystine in $0.17 \mathrm{~mol} \mathrm{~kg}^{-1} \mathrm{NaCl}$, which mimics the plasma ionic strength, lies somewhere between 0.93 $\times 10^{-3}$ and $1.02 \times 10^{-3} \mathrm{~mol} \mathrm{~kg}^{-1}$. This represents the saturation limit in a condition corresponding to a physiological environment and is best compared with homocystine levels that were previously measured in the vascular tissue [23], according to the view that in- tracellular homocysteine is likely the form that triggers adverse cellular events [14].

\section{Discussion}

In assessing a comparison between normal vascular tissue and atherogenic tissue obtained from occluded coronary artery, Tyagi and co-workers [23] provided evidence that elevation of OHcyE in the pathological tissue $(1.5 \pm 0.3 \mu \mathrm{g}$ per $\mathrm{mg}$ of total protein versus a $\sim 15$-fold lower concentration in normal controls) is much larger than the pathologically significant increase reported for plasma homocysteine and is likely respon- 


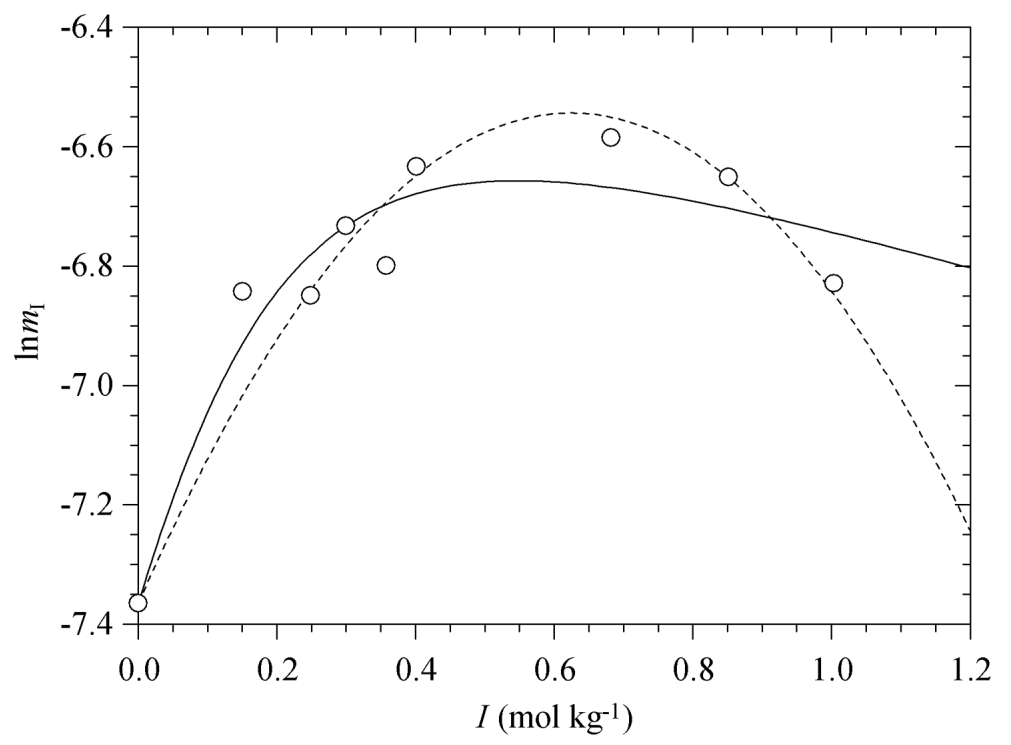

Fig. 4. Solubility of $D L$-homocystine at $37^{\circ} \mathrm{C}$ as a function of the ionic strength. The curves represent best fitting of experimental data to equation 1 (dashed) or 2 (solid), where $\ln m_{I}$ is the natural logarithm of the solubility and $I$ the ionic strength expressed in mol kg-1.

sible for the development of atherosclerotic lesions and vascular dysfunction. Taking into account that the mass of water in the adult human heart is $\sim 4$-fold the protein content [31], we have converted these values into the molal concentration units used here and estimated that the levels of OHcyE previously reported [23] amount to $\sim 0.9-1 \times 10^{-4}$ and $\sim 1.4-1.5 \times 10^{-3} \mathrm{~mol} \mathrm{~kg}^{-1}$ in normal and atherogenic tissue, respectively. To substantiate this datum, we have then compared the OHcyE levels in the atherogenic tissue with the solubility of homocystine at the plasma ionic strength $(\sim 0.93-1.02$ $\times 10^{-3} \mathrm{~mol} \mathrm{~kg}^{-1}$ in $0.17 \mathrm{~mol} \mathrm{~kg}^{-1} \mathrm{NaCl}$ at $37^{\circ} \mathrm{C}$, see Results).

As the solubility of the cysteine-homocysteine disulphide is expected to be intermediate between the solubilities of cystine $\left(\sim 5 \times 10^{-4} \mathrm{~mol} \mathrm{~kg}^{-1}\right.$ in $0.2 \mathrm{~mol}$ $\mathrm{kg}^{-1} \mathrm{NaCl}$ at $25^{\circ} \mathrm{C}$ [27]) and homocystine (as measured by us), it is apparent that the concentration reached by OHcyE in the atherogenic tissue almost exactly matches their saturation limit in vitro, which implies that OHcyE levels in the injured tissue are saturating. This conclusion is strenghtened by two further observations. First, the statistical variability of the OHcyE elevation in the atherogenic tissue, as previously reported [23], is significantly lower than that usually observed from population studies on plasma levels. In general, saturating conditions are characterized by reduced dispersion of measurements, because the concentration of the solute in equilibrium with the solid phase is constant and not anymore affected by linkage with other equilibria. Second, the saturation concentration of OHcyE in the tissue is expected to be even lower compared to blood levels, owing to the lower ionic strength of tissue fluids.

Compared to the prediction of homocystine solubility and to the hypothesis that the bloodstream could be the possible location of near-saturation levels of OHcyE [20], the measurements that we have now performed substantiate the view that significant leakage of intracellular fluid can promote OHcyE crystallization in vascular tissue. On this basis, we speculate that deposition of homocystine and/or cysteine-homocysteine crystals could be along the causal pathway that leads to vascular dysfunction, in much the same manner as a concentration of sodium urate above the solubility level is most likely the culprit responsible for gout. In the case of gout, however, chronic cumulative urate crystal formation in tissue fluids leads to urate deposition in tissues as tophi, but no evidence has ever been presented in the scientific literature in the 75 years since the discovery of homocystine to support our conclusion about deposition of OHcyE crystals. To this we reply that deposition of OHcyE could result in the formation of microcrystals in the tissue, but not in massive accumulations, thus being hard to recognize with the naked eye or even with usual diagnostic tools, and demanding investigation taking adequately aim at their identification.

Understanding the physicochemical properties of OHcyE deposition in vitro is of foremost importance, 
in the light of the differences previously observed between normal vascular tissue and atherogenic tissue obtained from occluded coronary artery [23]. As stated above, in all cases of biocrystallization, the transition to the solid phase may be influenced by other species dissolved in intracellular water, such as amino acids, glucose, uric acid, proteins, lipids, polysaccharides, etc. However, alteration of the OHcyE solubility mostly depends on ionic strength modifications, which in turn depend on the concentration of ionic species. As such, $\mathrm{NaCl}$ alone, which is by far the most populated ionic species, and therefore the major determinant of ionic strength in the body fluids, should be sufficient to mimic major effects that may occur in vivo.

As a matter of fact, our measurements show that the saturation limit of homocystine dissolved in an $\mathrm{NaCl}$ solution of concentration close to the plasma ionic strength is roughly two orders of magnitude higher than the levels of total plasma homocysteine present in both cardiovascular disease and normal patients [23, 32]. As a consequence, OHcyE may achieve saturation in the atherogenic tissue. Based on the concept that plasma homocysteine may be released from damaged tissues, this seems to support the view that elevated levels of total plasma homocysteine may represent, at least in part, the effect, and not solely the cause, of vascular dysfunction [33], since repair of DNA, RNA, and protein involves methylation and increased generation of S-adenosylhomocysteine and homocysteine within the cell [34]. This also means that total plasma homocysteine might not be the most appropriate index for cardiovascular risk [14], and most clinical applications should adopt OHcyE as a more direct marker, also considering that, based on a thorough review of the published literature, homocysteine has not met all of the stated criteria required for acceptance as a biomarker for risk assessment in primary prevention [35]. We also believe that prevention and treatment of vascular disease would be greatly improved by the comprehension of mechanisms causing OHcyE saturation in the atherogenic tissue.

\section{Acknowledgements}

Funding sources supporting this work were from the Council for Scientific Research of the Regione Campania, Italy.

\section{References}

[1] L.J. Langman and D.E.C. Cole, Homocysteine: cholesterol of the 90s? Clin Chim Acta 286 (1999), 63-80.

[2] G.J. Hankey and J.W. Eikelboom, Homocysteine and vascular disease, Lancet 354 (1999), 407-413.

[3] S. Seshadri, A. Beiser, J. Selhub, P.F. Jacques, I.H. Rosenberg, R.B. D'Agostino, P.W. Wilson and P.A. Wolf, Plasma homocysteine as a risk factor for dementia and Alzheimer's disease, N Engl J Med 346 (2002), 476-483.

[4] J. Selhub, Public health significance of elevated homocysteine, Food Nutr Bull 29 (2008), S116-S125.

[5] J.D. Finkelstein and J.J. Martin, Homocysteine, Int J Biochem Cell Biol 32 (2000), 385-389.

[6] E. Falk, J. Zhou and J. Moller, Homocysteine and atherothrombosis, Lipids 36 (2001), S3-S11.

[7] J. Selhub, The many facets of hyperhomocysteinemia: studies from the Framingham cohorts, J Nutr 136 (2006), 1726S1730 S.

[8] O. Nygård, S.E. Vollset, H. Refsum, L. Brattström and P.M. Ueland, Total homocysteine and cardiovascular disease, J Intern Med 246 (1999), 425-454.

[9] R. Castro, I. Rivera, H.J. Blom, C. Jakobs and I. Tavares de Almeida, Homocysteine metabolism, hyperhomocysteinaemia and vascular disease: an overview, J Inherit Metab Dis 29 (2006), 3-20.

[10] L.L. Humphrey, R. Fu, K. Rogers, M. Freeman and M. Helfand, Homocysteine level and coronary heart disease incidence: a systematic review and meta-analysis, Mayo Clin Proc 83 (2008), 1203-1212.

[11] A. D'Angelo and J. Selhub, Homocysteine and thrombotic disease, Blood 90 (1997), 1-11.

[12] S.R. Lentz, Mechanisms of homocysteine-induced atherothrombosis, J Thromb Haemost 3 (2005), 1646-1654.

[13] D.W. Jacobsen, Homocysteine and vitamins in cardiovascular disease, Clin Chem 44 (1998), 1833-1843.

[14] E.B. Stamm and R.D. Reynolds, Plasma total homocyst(e)ine may not be the most appropriate index for cardiovascular disease risk, J Nutr 129 (1999), 1927-1930.

[15] M.A. Mansoor, A.M. Svardal, J. Schneede and P.M. Ueland, Dynamic relation between reduced, oxidized, and proteinbound homocysteine and other thiol components in plasma during methionine loading in healthy men, Clin Chem 38 (1992), 1316-1321.

[16] N. Weiss, C. Keller, U. Hoffmann and J. Loscalzo, Endothelial dysfunction and atherothrombosis in mild hyperhomocysteinemia. Vasc Med 7 (2002), 227-239.

[17] N. Weiss, S.J. Heydrick, O. Postea, C. Keller, J.F. Jr. Keaney and J. Loscalzo, Influence of hyperhomocysteinemia on the cellular redox state - impact on homocysteine-induced endothelial dysfunction, Clin Chem Lab Med 41 (2003), 14551461.

[18] R.C. Austin, S.R. Lentz and G.H. Werstuck, Role of hyperhomocysteinemia in endothelial dysfunction and atherothrombotic disease, Cell Death Differ 11 (2004), S56-S64.

[19] P. Libby, Inflammation in atherosclerosis, Nature 420 (2002), 868-874.

[20] R. Ragone, Homocystine solubility and vascular disease, FASEB J 16 (2002), 401-404.

[21] E. Königsberger, Z. Wang and L.-C. Königsberger, Solubility of $L$-cystine in $\mathrm{NaCl}$ and artificial urine solutions, Monatsh Chem 130 (1999), 39-45.

[22] T. Knoll, A. Zöllner, G. Wendt-Nordahl, M.S. Michel and P. Alken, Cystinuria in childhood and adolescence: recom- 
mendations for diagnosis, treatment, and follow-up, Pediatr Nephrol 20 (2005), 19-24.

[23] S.C. Tyagi, L.M. Smiley, V.S. Mujumdar, B. Clonts and J.L. Parker, Reduction-oxidation (Redox) and vascular tissue level of homocyst(e)ine in human coronary atherosclerotic lesions and role in extracellular matrix remodeling and vascular tone. Mol Cell Biochem 181 (1998), 107-116.

[24] S. Sengupta, C. Wehbe, A.K. Majors, M.E. Ketterer, P.M. DiBello, D.W. Jacobsen, Relative roles of albumin and ceruloplasmin in the formation of homocystine, homocysteinecysteine-mixed disulphide, and cystine in circulation, $J$ Biol Chem 276 (2001), 46896-46904.

[25] P.J. Lee and A. Briddon, A rationale for cystine supplementation in severe homocystinuria, J Inherit Metab Dis 30 (2007), 35-38.

[26] E. Königsberger and L.-C. Königsberger, Thermodynamic modeling of crystal deposition in humans, Pure Appl Chem $\mathbf{7 3}$ (2001), 785-797.

[27] E.J. Cohn, T.L. McMeekin and M.H. Blanchard, Studies in the physical chemistry of amino acids, peptides, and related substances: XI. The solubility of cystine in the presence of ions and another dipolar ion, J Gen Physiol 21 (1938), 651663.

[28] E.N. Tsurko and N.V. Bondarev, Interparticle interaction in solutions of beta-alanine, valine and glutamic acid from concentration dependence of activity coefficients of their charged and zwitterionic forms at various ionic strengths, $J$ Mol Liquids 113 (2004), 29-36.

[29] K.S. Pitzer, A thermodynamic model for aqueous solutions of liquid-like density, Rev Mineral Geochem 17 (1987), 97-142.

[30] K.S. Pitzer, Ion interaction approach: theory and data correlation, in: Activity coefficients in electrolyte solutions, (2nd edn), K.S. Pitzer, ed., CRC Press, Boca Raton, 1991, pp. 75-153.

[31] R.M. Forbes, H.H. Mitchell and A.R. Cooper, Further studies on the gross composition and mineral elements of the adult human body, J Biol Chem 223 (1956), 969-975.

[32] S.S. Moselhy and S.H. Demerdash, Plasma homocysteine and oxidative stress in cardiovascular disease, Dis Markers 19 (2003-2004), 27-31.

[33] N.P. Dudman, An alternative view of homocysteine, Lancet 354 (1999), 2072-2074.

[34] M.A. Hofmann, E. Lalla, Y. Lu, M.R. Gleason, B.M. Wolf, N. Tanji, L.J. Jr. Ferran, B. Kohl, V. Rao, W. Kisiel, D.M. Stern and A.M. Schmidt, Hyperhomocysteinemia enhances vascular inflammation and accelerates atherosclerosis in a murine model, J Clin Invest 107 (2001), 675-683.

[35] G.L. Myers, R.H. Christenson, M. Cushman, C.M. Ballantyne, G.R. Cooper, C.M. Pfeiffer, S.M. Grundy, D.R. Labarthe, D. Levy, N. Rifai and P.W. Wilson, National Academy of Clinical Biochemistry Laboratory Medicine Practice guidelines: emerging biomarkers for primary prevention of cardiovascular disease, Clin Chem 55 (2009), 378-384. 


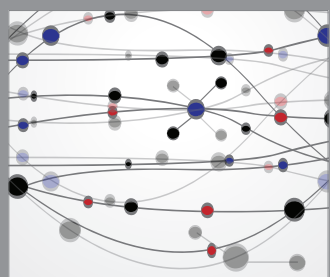

The Scientific World Journal
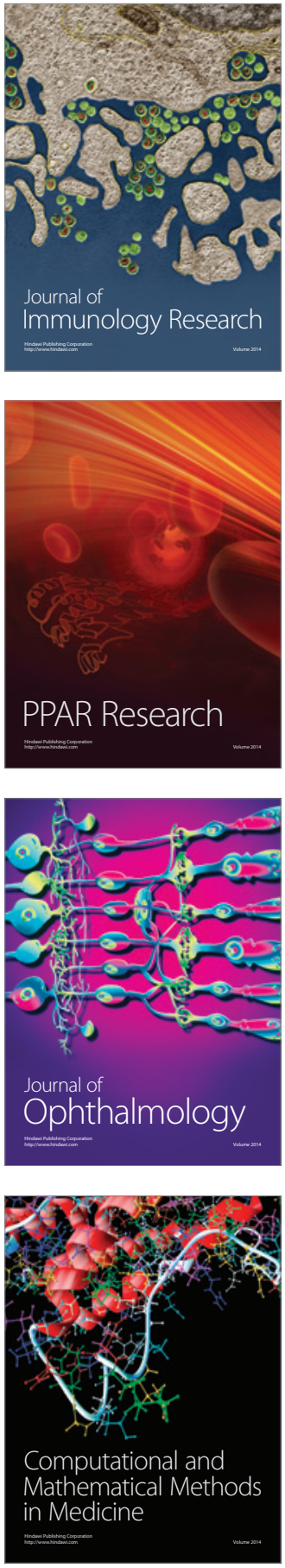

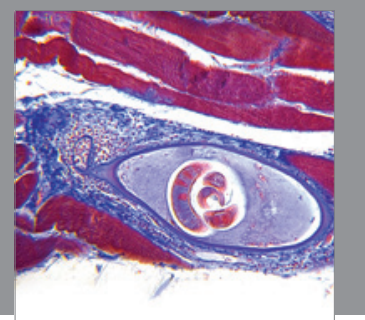

Gastroenterology

Research and Practice
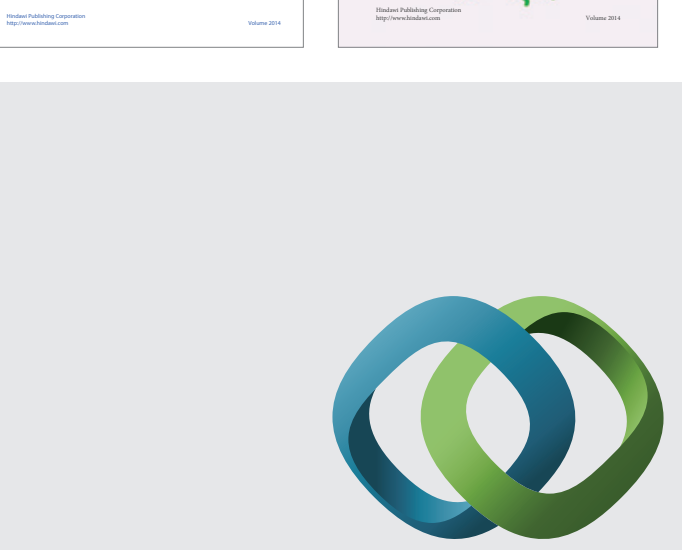

\section{Hindawi}

Submit your manuscripts at

http://www.hindawi.com
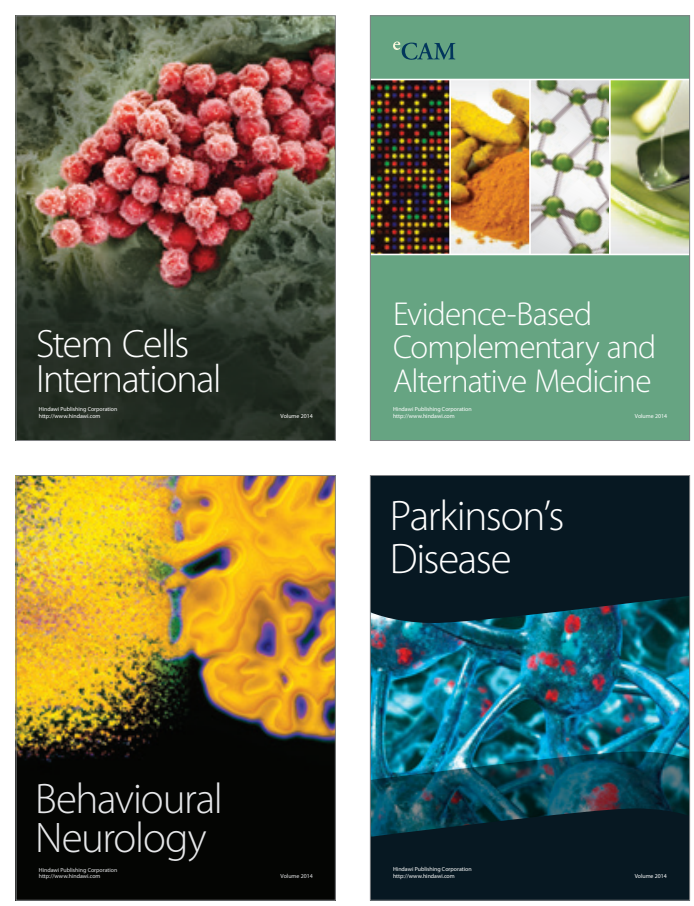

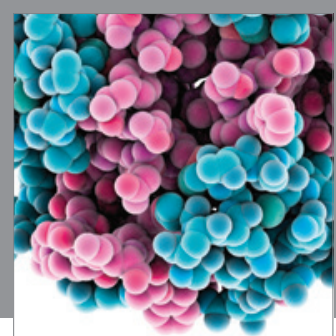

Journal of
Diabetes Research

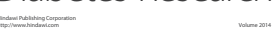

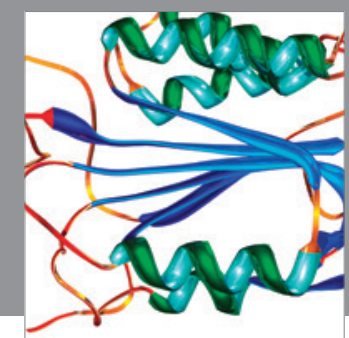

Disease Markers
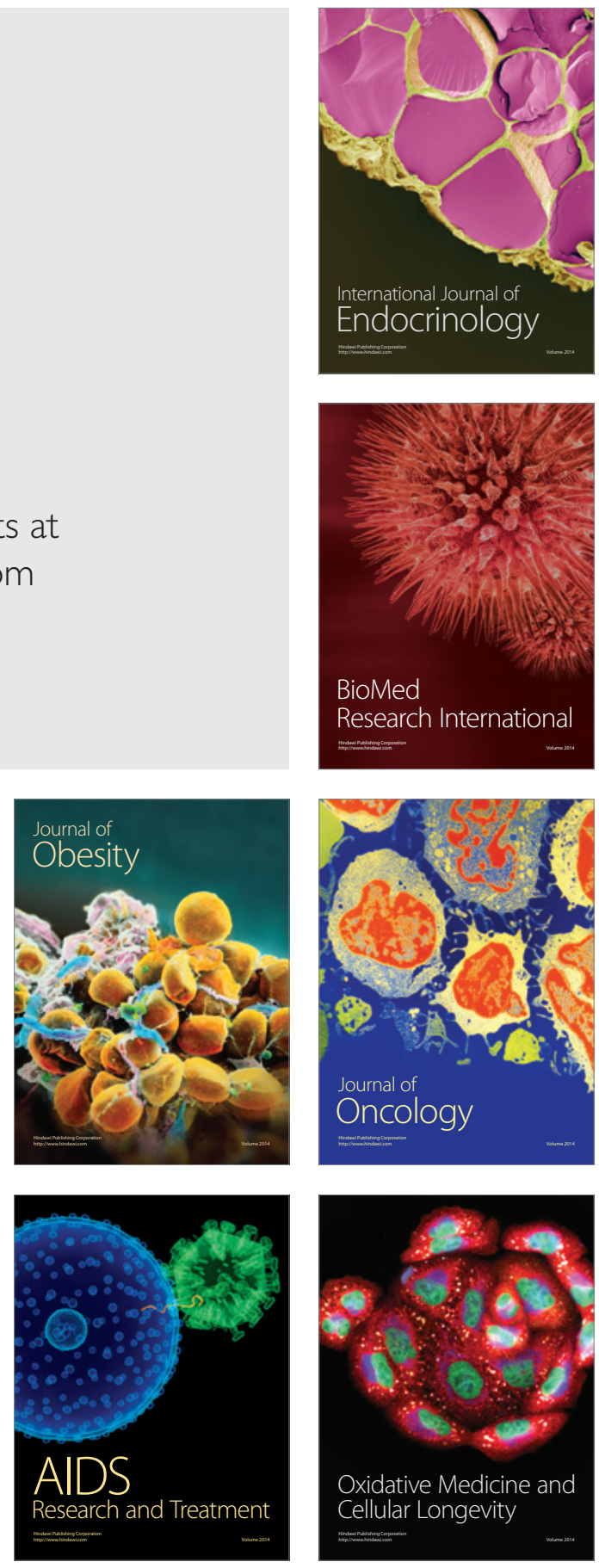